\title{
PENGARUH PENERAPAN METODE DISCOVERY LEARNING TERHADAP KEAKTIFAN BELAJAR SISWA PADA MATA PELAJARAN IPS KELAS VII DI MTS THAMRIN YAHYA KECAMATAN RAMBAH HILIR
}

\author{
Kurniati $^{1}$, Rina Ari Rohmah ${ }^{2}$ \\ Universitas Pasir Pengaraian \\ Nia896399@gmail.com, rinaarirohmah@gmail.com
}

\begin{abstract}
Abstrak
Penelitian ini bertujuan untuk mengetahui ada atau tidaknya pengaruh penerapan metode discovery learning terhadap keaktifan belajar siswa pada mata pelajaran IPS kelas VII di MTs Thamrin Yahya Kecamatan Rambah Hilir. Penulis menggunakan metode penelitian eksperimen semu. Hasil penelitian ini menunjukkan bahwa terdapat pengaruh yang signifikan metode pembelajaran discovery learning terhadap keaktifan belajar siswa. Hal ini dapat dilihat dari perbedaan kelas eksperimen dan kelas kontrol. Pada kelas eksperimen menggunakan metode discovery learning memiliki skor tertinggi 95 dan skor terendah 56 dengan nilai rata-rata 75,24. Pada kelas kontrol menggunakan metode konvensional memiliki skor tertinggi 85 dan skor terendah 59 dengan skor rata-rata 70,58. Penggunaan metode discovery learning lebih tinggi dibandingkan dengan metode konvensional. Pada uji hipotesis Jika $t_{h i t u n g}$ lebih besar dari $t_{\text {tabel }}$ maka $\mathrm{H}_{\mathrm{a}}$ diterima dan $\mathrm{H}_{0}$ ditolak. Dari perhitungan $t_{\text {hitung }}$ sebesar 1,692 dibandingkan dengan $t_{\text {tabel }}(\mathrm{df} 56$ yaitu 0,2586 taraf signifikan $5 \%$ jadi $t_{\text {hitung }}>\mathrm{t}_{\text {tabel }}$ maka $\mathrm{H}_{\mathrm{a}}$ diterima dan $\mathrm{H}_{0}$ ditolak.
\end{abstract}

Kata kunci: Discovery learning, keaktifan siswa, pelajaran IPS

\section{PENGARUH PENERAPAN METODE DISCOVERY LEARNING TERHADAP KEAKTIFAN BELAJAR SISWA PADA MATA PELAJARAN IPS KELAS VII DI MTS THAMRIN YAHYA KECAMATAN RAMBAH HILIR}

\author{
Kurniati \\ Universitas Pasir Pengaraian \\ Nia896399@gmail.com, rinaarirohmah@gmail.com
}

\begin{abstract}
This study aims to determine whether or not there is an effect of the application of the discovery learning method on student learning activities in social studies subjects grade VII at MTs Thamrin Yahya, Rambah Hilir. The author uses a quasi-experimental research method. The results of this study indicate that there is a significant effect of discovery learning learning methods on student learning activities. This can be seen from the difference between the experimental class and the control class. In the experimental class using the discovery learning method, the highest score was 95 and the lowest score was 56 with an average value of 75.24. The control class using the conventional method had the highest score of 85 and the lowest score of 59 with an average score of 70.58 . The use of discovery learning methods is higher than conventional methods. In hypothesis testing, if t_countt is greater than $t_{-}$table, then $H_{-}(a)$ is accepted and $H_{-}(0)$ is rejected. From the calculation t_count is 1.692 compared to t_table (df 56 is 0.2586 significant level 5\% so t_count > t_table then $H_{-}$a is accepted and $H_{-} O$ is rejected.
\end{abstract}

Keywords: Discovery learning, student activity, social studies lessons 


\section{Pendahuluan}

Pendidikan merupakan usaha sadar manusia untuk menumbuhkan dan mengembangkan potensi-potensi pembawaan baik jasmani maupun rohani sesuai dengan nilai-nilai yang ada didalam masyarakat dan kebudayaan $(\mathrm{H}$. Fuad Ihsan 2005:1). Tujuan pendidikan nasional sesuai dengan UU RI tentang sistem pendidikan nasional No (20 tahun 2003) yaitu "Pendidikan Nasional berfungsi mengembangkan kemampuan dan membentuk watak serta peradaban bangsa yang bermanfaat dalam rangka mencerdaskan kehidupan bangsa, bertujuan untuk mengembangkan potensi peserta didik agar menjadi manusia yang beriman dan bertakwa kepada tuhan yang Maha Esa, berahlak mulia, sehat, berilmu, cakap, kreatif, mandiri, dan menjadi warga negara yang demokratis dan bertanggung jawab.

Pendidikan merupakan serangkaian proses belajar yang harus dilalui oleh setiap oleh setiap orang untuk mencapai kehidupan yang lebih baik. Langkah yang dilakukan untuk menghasilkan sumber daya manusia yang berkualitas harus didukung dari aspek pembelajaran yang berkualitas dan baik. Menurut Oemar Hamalik (2010) belajar adalah bukan suatu tujuan tetapi merupakan proses untuk mencapai tujuan. Belajar adalah memodifikasi atau memperteguh kelakuan melalui pengalaman. Pendapat lain menyatakan bahwa belajar adalah suatu proses yang ditandai dengan adanya perubahan pada diri seseorang. Perubahan hasil proses belajar dapat ditunjukkan dalam berbagai bentuk seperti penambahan pengetahuan, pemahaman, sikap dan tingkah laku, kecakapan, kebiasaan serta perubahan aspek-aspek lain ada pada individu-individu yang belajar (Sudjana, 2010).

Selama ini pembelajaran yang disampaikan guru dalam pelajaran IPS terpadu masih terpusat pada guru yakni menjelaskan materi dari awal hingga akhir dan membuat peserta didik tidak aktif. Hasil wawancara saat prapenelitian pada tanggal 10 Oktober 2020 dengan guru mata pelajaran IPS MTs Thamrin Yahya menyatakan bahwa untuk kelas VII guru-guru mengajar mengunakan metode ceramah yang membuat siswa tersebut tidak aktif, sibuk bercerita dan tidak serius dalam proses pembelajaran. Dari hasil observasi tersebut peneliti tertarik untuk melakukan penelitian di kelas VII 1, VII 2, VII 3, VII 4. Peneliti menemukan bahwa siswa-siswa terlihat tidak mampu dalam memecahkan masalah, tidak mampu bekerjasama dalam kelompok, tidak mengemukakan pendapat, kurang memperhatikan pelajaran.

Berdasarkan keadaan tersebut, untuk dapat meningkatkan keaktifan belajar siswa saat pembelajaran berlangsung diperlukan penerapan metode pembelajaran yang tepat yang disesuaikan dengan tujuan dan karakteristik mata pelajaran serta kondisi siswa. Guru yang kreatif berusaha untuk memilih metode yang serasi juga sedapat mungkin diselingi yang baru sehingga siswa merasakan adanya kesegaran ketika menerima pelajaran di kelas, terhindar dari rasa bosan dan mengantuk bahkan pelajaran dirasakan tidak sulit dan menjadi disenangi. Untuk mengatasi masalah keaktifan belajar agar tidak berkelanjutan digunakan lah metode pembelajaran aktif yaitu suatu pembelajaran yang mengajak siswa untuk belajar secara aktif. Strategi pembelajaran aktif adalah suatu pembelajaran yang 
mengajak siswa untuk belajar aktif (Hisyam Zaini, 2007). Menurut Sudjana (2004:61), indikator keaktifan yang digunakan untuk pembuatan angket keaktifan siswa adalah sebagai berikut: pemecahan masalah, kerjasama, mengemukakan gagasan, dan perhatian.

Adapun untuk mengatasi metode guru yang kurang menarik dalam pembelajara IPS, salah satunya menggunakan metode discovery learning. Metode discovery learning adalah memahami konsep, arti, dan hubungan, melalui proses intuitif untuk akhirnya sampai pada suatu kesimpulan. Discovery learning dilakukan melalui observasi, klasifikasi, pengukuran, prediksi, penentuan. Proses tersebut disebut cognitive process sedangkan discovery itu sendiri adalah the mental process of assimilatig conceps and principles in the mind (Budiningsih, 2005:43).

Peran guru dalam metode discovery learning adalah sebagai pengajar atau pendidik dengan memberikan kesempatan kepada siswa untuk belajar secara aktif. Guru harus dapat membimbing dan mengarahkan kegiatan belajar siswa sesuai dengan tujuan dalam metode discovery learning. Didalam metode discovery learning bahan ajar tidak di sajikan dalam bentuk akhir siswa dituntut untuk melakukan berbagai kegiatan menghimpun informasi,membandingkan, mengategorikan, menganalisis, mengintegrasikan, dan mengorganisasikan bahan serta membuat kesimpulan (Sardiman, 2001:145).

Kondisi seperti ini ingin mengubah kegiatan belajar mengajar yang teacher oriented menjadi student oriented. Menurut Hosnan (2014:287), kelebihan penerapan discovery learning yaitu membantu siswa untuk memperbaiki dan meningkatkan keterampilan-keterampilan dan proses-proses kognitif berupa usaha untuk menemukan yang merupakan kunci dalam proses ini sehingga pengetahuan yang diperoleh melalui metode ini sangat pribadi dan ampuh karena menguatkan pengertian, ingatan, dan transfer.

Terkait dengan metode Discovery Learning, sebelumya pernah diteliti oleh Dede Nur Hasanah tahun (2018) dengan judul "Penggunaan model pembelajaran discovery learning untuk meningkatkan kemampuan pemecahan masalah pada siswa SMP". Hasil penelitian menunjukkan adanya peningkatan aktivitas siswa ketika pembelajaran sebesar 4 dari nilai maksimal 5 dan hal itu termasuk dalam kategori baik. Selain itu, penelitian dengan metode discovery learning juga pernah diteliti oleh Yulia Ayuningsih Salo (2016) dengan judul "Pengaruh metode discovery learning terhadap keaktifan belajar siswa (studi quasi eksperimen kelas VII SMPN 6 Banda Aceh)". Hasil penelitian setelah diberikan metode discovery learning pada kelompok esperimen keaktifan belajar siswa meningkat, dari 30 siswa terdapat 8 orang siswa mengalami peningkatan menjadi kategori tinggi atau sebesar 26,7\%, 22 siswa pada kategori sedang atau sebesar 73,3 \% dan tidak terdapat keaktifan belajar pada kategori rendah.

Berdasarkan hasil permasalahan di atas tampak bahwa dengan penggunaan metode discovery learning dapat meningkatkan keaktifan siswa selama pembelajaran. Oleh karena itu, penelitian ini penting dilakukan untuk mengungkapkan ada atau tidaknya pengaruh penerapan metode discovery learning terhadap keaktifan belajar siswa pada mata pelajaran IPS di kelas VII MTs Thamrin Yahya. 


\section{Metode Penelitian}

Jenis penelitian ini adalah penelitian kuantitatif. Metode penelitian ini menggunakan metode eksperimen. Metode eksperimen adalah metode penelitian yang digunakan untuk mencapai pengaruh perlakuan tertentu. Pada penelitian ini yang digunakan adalah eksperimen semu (quasi eksperiment). Menurut Lufri (2007:62), jenis penelitian kuantitatif ini diambil karena tidak memungkinkan untuk memanipulasi atau mengontrol satu variabel-variabel dan kondisi-kondisi eksperimen secara tertib dan ketat. Quasi eksperimen adalah eksperimen yang memiliki perlakuan pengukuran-pengukuran dampak dan unit eksperimen namun tidak menggunakan penempatan secara acak.

Arikunto (2006:12) menyatakan bahwa penelitian kuntitatif yakni pendekatan penelitian yang banyak menggunakan angka-angka, mulai dari mengumpul data, penafsiran terhadap data yang diperoleh, serta pemaparan hasilnya.

Penelitian ini terdiri dari dua kelas yaitu kelas eksperimen dan kelas kontrol. Rancangan penelitian yang digunakan adalah menggunakan desain penelitian Posttest-Only Control Grub (Sugiyono, 2019:132).

\begin{tabular}{|c|c|c|}
\hline $\begin{array}{ll} & \mathrm{R} \\
\mathrm{R} & \end{array}$ & $X$ & $\mathrm{O} 2$ \\
\hline
\end{tabular}

Penelitian dilakukan di MTs Thamrin Yahya kelas VII. Penelitian ini membutuhkan waktu enam bulan dumulai pada bulan November 2020 sampai dengan bulan juli 2021. Menurut Sugiyono (2019:146), populasi adalah wilayah generalisasi yang terdiri atas obyek/subyek yang mempunyai kualitas dan karakteristik tertentu yang ditetapkan oleh peneliti untuk dipelajari dan kemudian ditarik kesimpulannya. Populasi dalam penelitian ini adalah siswa kelas VII MTs Thamrin Yahya Rambah Hilir yang terdiri dari 4 kelas yang berjumah 117 orang. Teknik pengambilan sampel yang digunakan yaitu simple random sampling. Menurut Margono (2004:126), simple random sampling adalah teknik untuk mendapatkan sampel yang langsung dilakukan pada unit sampling. Cara menentukan sampel dari teknik simple random sampling adalah dengan cara pengundian. Hasil undian tersebut menunjukkan bahwa kelas VII 3 sebagai kelas eksperimen dan VII 4 sebagai kelas kontrol.

Penelitian ini merupakan penelitian kuantitatif yang datanya berupa angkaangka. Adapun jenis dan sumber data yang digunakan dalam penelitian yaitu sumber data primer dan sumber data sekunder. Pengumpulan data yang digunakan dalam penelitian ini adalah angket. Instrumen penelitian yaitu tahap uji coba, uji validitas, uji reliabilitas.

Hasil uji validitas terdapat 50 item pernyataan. Dari 50 item pernyataan 28 item yang dinyatakan valid yaitu $r_{\text {hitung }}$ masing-masing item pernyataan > $r_{\text {tabel }}(0,361)$ sehingga angket atau item pernyataan dinyatakan valid, sedangkan 22 item pertanyaan yang lainnya dinyatakan tidak valid yaitu $r_{\text {hitung }}$ masing- 
masing item pernyataan $<r_{\text {tabel }}(0,361)$ sehingga angket atau item pertanyaan dinyatakan tidak valid. Pernyataan yang tidak valid dibuang atau tidak dipakai lagi.

Pada uji reliabilitas yang dihitung merupakan pernyataan yang akan digunakan sebagai tes. Dilihat dari tabel klasifikasi koefesien reliabilitas alat ukur yang reliabilitasnya yang tinggi dinyatakan alat ukur yang reliable. Berikut ini tabel uji reliabilitas:

Tabel 3.8 Hasil Analisis Uji Reliabilitas

\begin{tabular}{cc}
\hline & Reliability Statistics \\
\hline Cronbach's & \\
Alpha & N of Items \\
, 921 & 28 \\
\hline
\end{tabular}

Sumber data: SPSS 18.0

Dari hasil uji reliabilitas yang telah dilakukan diperoleh nilai $r_{11}$ sebesar 0,893, maka angket tersebut dapat dikatakan memiliki reliabilitas berkategori sangat tinggi.

\section{Hasil dan Pembahasan}

Hasil penelitian yang dilakukan dikelas eksperimen untuk mengetahui keaktifan belajar siswa. Kelas eksperimen berjumlah 29 siswa diberikan angket pernyataan dengan jumlah 28 item dengan skala keaktifan belajar siswa lima pilihan jawaban. Hasil dari angket atau pernyataan diperoleh nilai rata-rata kelas eksperimen sebesar 75,24, nilai standar deviasi sebesar 10,248, dan nilai maksimum sebesar 95, nilai minimum sebesar 56.

Berdasarkan hasil analisis diketahui bahwa keaktifan belajar siswa kelas eksperimen diperoleh nilai tertinggi sebesar 95 dan nilai terendah 56. Jumlah interval ditentukan dengan rumus $K=1+3,3 \log 29$, hasilnya adalah 5,82 atau 5. Rentang data (RD) diperoleh dari $90-56=39$, sedangkan panjang kelas didapatkan dari rentang dibagi dengan jumlah $(39 / 5=7,8)$ dibulatkan menjadi 8 . Berdasarkan hasil rekapitulasi, dapat dibuat tabel distribusi frekuensi sebagai berikut:

1.4 Tabel Distribusi Frekuensi Kelas Eksperimen

\begin{tabular}{ccc}
\hline Interval skor & Frekuensi & Persen\% \\
\hline $56-63$ & 5 & $17,24 \%$ \\
$64-71$ & 6 & $20,68 \%$ \\
$72-79$ & 7 & $24,13 \%$ \\
$80-87$ & 6 & $20,68 \%$ \\
$88-95$ & 5 & $17,24 \%$ \\
Jumlah & 29 & $99.97 \%$
\end{tabular}

Sumber: Pengolahan data primer 2021 
Berdasarkan tabel distribusi frekuensi data keaktifan siswa di atas, dapat diketahui bahwa 7 siswa atau $24,13 \%$ dari jumlah siswa memperoleh nilai ratarata, yaitu 75,24, siswa yang memperoleh nilai di bawah kelas interval rata-rata berjumlah 11 orang siswa atau sebesar 37,92\%, sedangkan siswa yang memperoleh nilai di atas kelas interval rata-rata berjumlah 11 orang siswa atau sebesar 41,37\%. Berikut ini data distribusi kelas eksperimen dapat disajikan dalam bentuk diagram sebagai berikut:

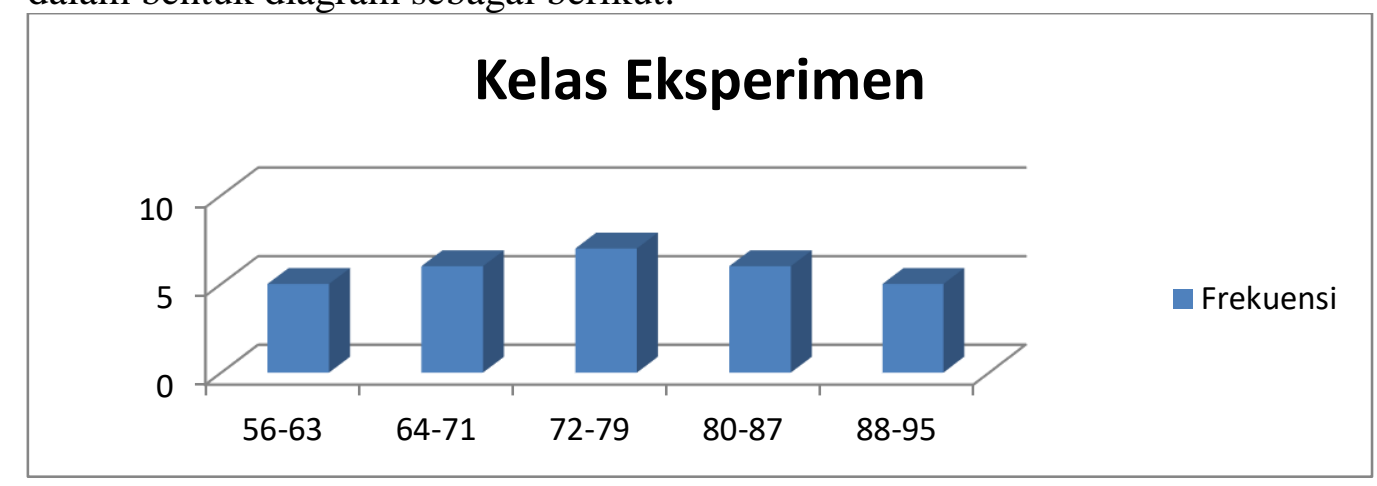

Sumber: Pengolahan data primer 2021

Hasil penelitian yang dilakukan dikelas kontrol untuk mengetahui kekatifan belajar siswa. Kelas kontrol berjumlah 29 siswa diberikan angket pernyataan dengan jumlah 28 item dengan skala keaktifan belajar siswa lima pilihan jawaban. Hasil dari angket atau pernyataan diperoleh nilai rata-rata kelas kontrol sebesar 70,58 nilai standar deviasi sebesar 10,248, dan nilai maksimum sebesar 86 dan nilai minimum sebesar 59.

Berdasarkan hasil analisis diketahui bahwa keaktifan belajar siswa kelas kontrol diperoleh nilai tertinggi sebesar 85 dan nilai terendah 59. Jumlah interval ditentukan dengan rumus $\mathrm{K}=1+33 \log 29$, hasilnya adalah 5,82 atau 6 . Rentang data (RD) diperoleh dari $85-59=26$, sedangkan panjang kelas didapatkan dari rentang dibagi dengan jumlah $(26 / 5=5,2)$ dibulatkan menjadi 5 . Berdasarkan hasil rekapitulasi, dapat dibuat tabel distribusi frekuensi sebagai berikut:

\subsection{Distribusi Frekuensi Kelas Kontrol}

\begin{tabular}{ccc}
\hline Interval skor & Frekuensi & Persen\% \\
\hline $59-63$ & 4 & $13,79 \%$ \\
$64-68$ & 2 & $6,89 \%$ \\
$69-73$ & 6 & $20,68 \%$ \\
$74-78$ & 10 & $34,48 \%$ \\
$79-83$ & 5 & $17,24 \%$ \\
$84-88$ & 2 & $6,89 \%$ \\
Jumlah & 29 & $99,97 \%$
\end{tabular}

Sumber: Pengolahan data primer 2021 
Berdasarkan tabel distribusi frekuensi data keaktifan siswa di atas, dapat diketahui bahwa 10 siswa atau 34,48\% dari jumlah siswa memperoleh nilai ratarata yaitu 70,58, siswa yang memperoleh nilai di bawah kelas interval rata-rata berjumlah 6 orang siswa atau sebesar 20,68\%, sedangkan siswa yang memperoleh nilai di atas kelas interval rata-rata berjumlah 7 orang siswa atau sebesar $24,13 \%$. Berikut ini data distribusi kelas kontrol dapat disajikan dalam bentuk diagram sebagai berikut:

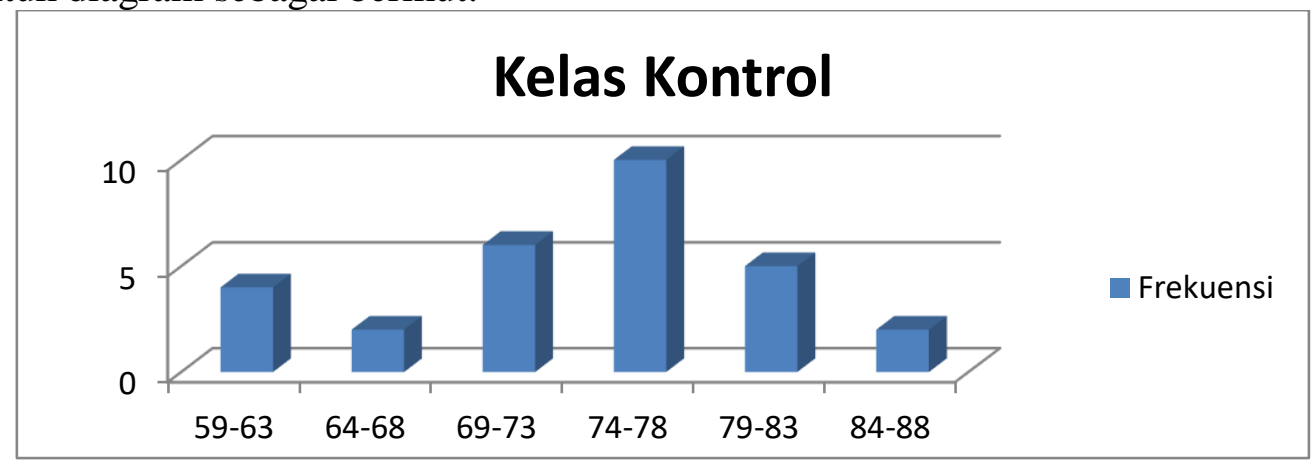

Sumber: Pengolahan data primer 2021

Uji normalitas dilakukan untuk mengetahui apakah populasi berasal dari data yang berdistribusi normal dengan menggunakan rumus uji liliefors dengan menggunakan taraf signifikan 0,05. Data berdistribusi normal jika signifikansi lebih besar dari 0,05 .

Tabel 3.4 Hasil Uji Normalitas Kelas Eksperimen Lilliefors Significance Correction

\begin{tabular}{|c|c|c|c|c|}
\hline \multicolumn{4}{|c|}{ Tests of Normality } & \\
\hline \multicolumn{3}{|c|}{ Kolmogorov-Smirnov ${ }^{a}$} & \multirow{2}{*}{$\begin{array}{c}\text { Shapiro-Wilk } \\
\text { Statistic }\end{array}$} & \\
\hline Statistic & Df & Sig. & & \\
\hline 121 & 29 & ,200* & & 964 \\
\hline
\end{tabular}

\section{Sumber: Output SPSS 18 diolah 2021}

Dari tabel Lilliefors Significance Correction diperoleh angka signifikan. Nilai ini akan dibandingkan dengan 5\% atau taraf signifikan 0,05 dasar dalam pengambilan keputusan dalam uji normalitas, menggunakan pedoman sebagai berikut:

1. Jika nilai Signifikansi $>0,05$ maka data berdistribusi normal.

2. Jika nilai Signifikansi $<0,05$ maka data tidak berdistribusi normal.

Berdasarkan hasil uji normalitas kelas eksperimen diketahui nilai signifikansi $0,200>0,05$, maka dapat disimpulkan bahwa data berdistribusi 
normal. Selanjutnya, pada kelas kontrol diketahui uji normalitas yang dijelaskan pada tabel berikut:

Tabel 4.4 Hasil Uji Normalitas Kelas Kontrol Lilliefors Significance Correction

\begin{tabular}{|c|c|c|c|}
\hline \multicolumn{4}{|c|}{ Tests of Normality } \\
\hline & \multicolumn{3}{|l|}{$\begin{array}{l}\text { Kolmogorov- } \\
\text { Smirnov }^{\mathrm{a}}\end{array}$} \\
\hline & Statistic Df Sig. & Statistic Df & Sig. \\
\hline $\begin{array}{l}\text { DATA_NORMALITAS_KELAS_ } \\
\text { KONTROL }\end{array}$ & , 134 29,197 & ,951 29 & ,194 \\
\hline
\end{tabular}

Dari tabel Lilliefors Significance Correction diperoleh angka signifikan. Nilai ini akan dibandingkan dengan 5\% atau taraf signifikan 0,05. Dasar dalam pengambilan keputusan dalam uji normalitas menggunakan pedoman sebagai berikut:

1. Jika nilai signifikansi $>0,05$ maka data berdistribusi normal.

2. Jika nilai signifikansi $<0,05$ maka data tidak berdistribusi normal.

Berdasarkan hasil uji normalitas kelas kontrol diketahui nilai signifikansi $0,197>0,05$, maka dapat disimpulkan bahwa data berdistribusi normal.

Tabel 5.4 Hasil Uji Homogenitas Kelas Eksperimen Dan Kelas Kontrol

Hasil Keaktifan Siswa

$$
\text { Test of Homogeneity of Variances }
$$

\begin{tabular}{|c|c|c|c|c|}
\hline \multirow[t]{2}{*}{ Levene Statistic } & & & df 2 & Sig. \\
\hline & 191 & 1 & 56 & .664 \\
\hline
\end{tabular}

Sumber: Output SPSS 18.0 diolah 2021

Berdasarkan tabel di atas hasil rekapitulasi uji homogenitas data kelas eksperimen dan kelas kontrol mempunyai taraf signifikan sebesar 0,664 > 0,05. Jadi dapat disimpulkan data tersebut homogen atau sama.

Dari hasil uji normalitas dan homogenitas diketahui bahwa kedua data atau kelas berdistribusi normal dan mempunyai varian yang sama. Selanjutnya uji hipotesis dilakukan dengan uji $\mathrm{t}$ yang bertujuan untuk apakah ada pengaruh penggunaan metode Discovery Learning terhadap keaktifan belajar siswa pada mata pelajaran IPS di Mts Thamrin Yahya. 
Tabel 6.4 Output Uji Hipotesis Independent Samples Test

\begin{tabular}{llrrr} 
& & \multicolumn{3}{c}{ t-test for Equality of Means } \\
& t & Df & $\begin{array}{c}\text { Sig. (2- } \\
\text { tailed) }\end{array}$ \\
\hline $\begin{array}{l}\text { Hasil_Keaktifan_Equal variances assumed } \\
\text { Siswa }\end{array}$ & 1,692 & 56 &, 096 \\
& $\begin{array}{l}\text { Equal variances not } \\
\text { assumed }\end{array}$ & 1,692 & 55,880 &, 096 \\
\hline
\end{tabular}

Sumber: Output SPSS 18.0 diolah 2021.

Dapat ditarik kesimpulan hasil penelitian, dilihat dari hasil penelitian yang diperoleh pada kelas eksperimen menggunakan metode discovery learning nilai rata-rata 75,24. Pada kelas kontrol menggunakan metode konvensional nilai ratarata 70,58. Dari indikator keaktifan belajar siswa terdapat capaian tertinggi dari pemecahan masalah yaitu bertanya kepada guru jika mengalami kesulitan capaian nya sebesar $74 \%$ dan capaian terendah dari perhatian yaitu tidak memperhatikan teman presentasi di depan kelas capaiannya sebesar $45 \%$. Hasil uji validitas dari 50 butir item pernyataan terdapan 28 item yang valid. Uji reliabilitas yang telah dilakukan diperoleh nilai $r_{11}$ sebesar 0,921. Hasil uji normalitas kelas eksperimen nilai signifikansi 0,200 dan Berdasarkan hasil uji normalitas kelas kontrol diketahui nilai signifikansi 0,197 . Hasil uji homogenitas data kelas eksperimen dan kelas kontrol mempunyai taraf signifikan sebesar 0,664 > 0,05. Jadi dapat disimpulkan data tersebut homogen atau sama. Uji hipotesis dari perhitungan $t_{\text {hitung }}$ sebesar 1,692 diatas dibandingkan dengan $t_{\text {tabel }}$ (df 56 yaitu 0,2586 taraf signifikan $5 \%$ jadi $t_{\text {hitung }}>t_{\text {tabel }}$ maka $H_{a}$ diterima dan $H_{0}$ ditolak. Dari analisis di atas dinyatakan "Ada pengaruh metode discovery learning terhadap keaktifan belajar siswa di kelas VII MTs Thamrin Yahya Kecamatan Rambah Hilir Tahun Pembelajaran 2020/2021”.

\section{Kesimpulan}

Berdasarkan hasil analisis data dan pembahasan dapat disimpulkan bahwa terdapat pengaruh yang signifikan metode pembelajaran discovery learning terhadap keaktifan belajar siswa. Dapat dilihat dari perbedaan kelas eksperimen dan kelas kontrol. Pada kelas eksperimen menggunakan metode discovery learning memiliki skor tertinggi 95 dan skor terendah 56 dengan nilai rata-rata 75,24. Pada kelas kontrol menggunakan metode konvensional memiliki skor tertinggi 85 dan skor terendah 59 dengan skor rata-rata 70,58. Penggunaan metode discovery learning lebih tinggi dibandingkan dengan metode konvensional.

Dilihat dari indikator keaktifan belajar siswa terdapat capaian tertinggi dari pemecahan masalah yaitu bertanya kepada guru jika mengalami kesulitan capaian nya sebesar $74 \%$ dan capaian terendah dari perhatian yaitu tidak memperhatikan teman presentasi di depan kelas capaiannya sebesar $45 \%$.. Pada uji hipotesis Jika $t_{\text {hitung }}$ lebih besar dari $t_{\text {tabel }}$ maka $\mathrm{H}_{a}$ diterima dan $\mathrm{H}_{0}$ ditolak. 
Dari perhitungan $t_{\text {hitung }}$ sebesar 1,692 dibandingkan dengan $t_{\text {tabel }}$ df 56 yaitu 0,2586 taraf signifikan $5 \%$ jadi $t_{\text {hitung }}>t_{\text {tabel }}$ maka $H_{a}$ diterima dan $\mathrm{Ho}$ ditolak. Dengan demikian, dapat diambil kesimpulan bahwa ada pengaruh metode discovery learning terhadap keaktifan belajar siswa di kelas VII MTs Thamrin Yahya Kecamatan Rambah Hilir Tahun Pembelajaran 2020/2021. Untuk meningkatkan keaktifan belajar siswa dapat digunakan metode discovery learning.

Saran yang dapat diberikan yaitu (1) Kepala sekolah dapat mengondisikan para guru untuk menggunakan metode discovery learning agar membantu para pendidik melaksanakan pembelajaran, sehingga dapat dijadikan referensi atau panutan untuk meningkatkan kualitas pembelajaran di sekolah, (2) Guru sebaiknya selalu memperhatikan keaktifan siswa dengan begitu pembelajaran akan menjadi lebih menyenangkan dan siswa tidak hanya diam disaat pembelajaran berlangsung, (3) Disarankan kepada siswa untuk meningkatkan keaktifan belajar agar saat proses pembelajaran IPS. , (4) Bagi peneliti selanjutnya sebagai panduan bagaimana cara meneliti tentang penerapan metode discovery learning untuk meningkatkan keaktifan belajar siswa.

\section{DAFTAR PUSTAKA}

Arikunto. 2006. Prosedur Suatu Pendekatan Praktek. Jakarta: PT. Rineka Cipta.

Depdiknas. 2003. Undang-undang RI No. 20 tahun 2003. Tentang Sistem Pendidikan Nasional.

Ihsan, Fuad. 2005. Dasar-Dasar Kependidikan. Jakarta: Rineka Cipta.

Lufri. 2007. Strategi Pembelajaran Biologi Teori, Praktek Dan Penelitian. UNP Press. Padang.

Margono. 2004. Metodologi Penelitian Pendidikan. Jakarta: Rineka Cipta.

Hamalik, Oemar. 2010. Proses Belajar Mengajar. Jakarta: PT Bumi Aksara.

Hasanah, Dede Nur. Penggunan Model Pembelajan Discovery Learning Untuk Meningkatkan Kemampuan Pemecahan Masalah Pada Siswa SMP. Jurnal Didactical Mathematisc, Vol 1 No 1 (Online).

Hosnan. 2014. Pendekatan Saintifik dan Konsektual dalam Pembelajaran Abad 21 Kunci Sukses Implementasi Kurikulum 2013. Bogor: ghalia indonesia.

Sardiman. 2001. Interaksi dan Motivasi Belajar Mengajaar. Jakarta: PT Raja Grafindo Persada.

Sudjana. 2004. Proses Hasil Proses Belajar Mengajar. Bandung: PT. Remaja Rosdakarya. 
Bakoba : Jurnal Pendidikan IPS, Vol. 01, No. 02, Agustus 2021 doi10.30606/bjpi.v01io1.xxx

Sugiyono. 2019. Metode Penelitian Pendidikan (kuantitatif, kualitatif,kombinasi, $R \& D$ dan penelitian pendidikan). Bandung: Alfabeta.

Salo, Yulia Ayuningsih. 2016. Pengaruh Metode Discovery Learning Terhadap Keaktifan Belajar Siswa (Studi Quasi Eksperimen Kelas VII SMPN 6 Banda Aceh. Jurnal Penelitian Pendidikan, Vol 16. No 3.

Zaini, Hisyam. 2007. Strategi Pembelajaran Aktif. Yogyakarta : Center for Teaching Staff Development (CTSD). 